\title{
Incorrect aseptic techniques in medicine preparation and recommendations for safer practices: a systematic review
}

\author{
Eeva Suvikas-Peltonen, Suvi Hakoinen, Ercan Celikkayalar, Raisa Laaksonen, \\ Marja Airaksinen
}

\begin{abstract}
- Additional material is published online only. To view please visit the journal online (http://dx.doi.org/ 10.1136/ejhpharm-2016001015).
\end{abstract}

Clinical Pharmacy Group, Division of Pharmacology and Pharmacotherapy, Faculty of Pharmacy, University of Helsinki, Finland

\section{Correspondence to} Eeva Suvikas-Peltonen, Sairaalantie 3, Pori 28500, Finland; eeva.suvikaspeltonen@satadiag.fi

Received 9 June 2016 Revised 14 September 2016 Accepted 20 September 2016 Published Online First 12 October 2016

EAHP Statement 3: Production and Compounding. EAHP Statement 5: Patient Safety and Quality Assurance

\section{Linked}

- http://dx.doi.org/10.1136/ ejhpharm-2016-001174

CrossMark

To cite: Suvikas-Peltonen $E_{\text {, }}$ Hakoinen S, Celikkayalar E, et al. Eur J Hosp Pharm 2017;24:175-181.

\begin{abstract}
Objective Many patient deaths have been reported because of administration of contaminated intravenous medicines due to incorrect aseptic techniques. Our aim was to review the literature for (1) incorrect practices in aseptic drug preparation and administration and (2) recommendations for safer practices in hospitals.

Methods A systematic literature search was conducted in PubMed covering 2007-2015. Studies were included if they concerned aseptic medicine preparation and administration in hospitals by different healthcare professionals, assessed incorrect practices and made recommendations for safer aseptic preparation and administration.
\end{abstract}

Results 26 studies were included of which 19 were original articles. 12 of the studies concerned description of incorrect practices that led to contamination. The studies reported 11 incorrect practices that increased the risk of contamination of parenteral medicines. The most reported incorrect practices were multiple use of phials and syringes (2/12 studies) and lack of overall disinfection during the aseptic preparation and administration (3/12 studies). 22 practices were recommended to avoid contamination, which were classified into six categories: equipment and medicines (7); disinfection (6); working environment (3); storing (3); catheter care (2) and quality of prepared medicines (1). The results indicate that pharmacists prepared syringes with less contamination than nurses because of the pharmacist's aseptic skills and environmental aspects in pharmacy units.

Conclusions The review discusses many appropriate and enhanced practices in aseptic drug preparation and administration. As the change for the better in contamination rates of administered medicines seems to be challenging to achieve in hospitals, better and possibly international procedures for safe parenteral practices need to be developed.

\section{INTRODUCTION}

Administration of contaminated intravenous medicines due to incorrect aseptic techniques has been a contributing factor to many of the patient deaths that have been reported. ${ }^{1}{ }^{2}$ Healthcare-associated infections are a significant cause of harm to patients and add remarkably to the healthcare costs all over the world. ${ }^{3}$ Intravenous therapy is a complex process sometimes requiring the preparation of a medicine in the hospital pharmacy premises or on the ward before administration to the patient. ${ }^{4}$ Thus, the preparation phase is posing a potential risk for microbial contamination. Therefore, aseptic techniques must be used when handling sterile starting components for the preparation of medicines for parenteral administration in order to reduce microbial contamination risk. ${ }^{5}$ Aseptic techniques are methods designed to prevent contamination from microorganisms. These techniques require application of the strictest rules and best knowledge of infection prevention in order to minimise the risks for infection. Common settings where aseptic techniques for preparation of medicines are needed include surgery rooms and clinics in hospitals, pharmacies and drug industry. According to a previous study, medication errors are common related to the parenteral medicines in hospitals. ${ }^{4}$ At least one deviation from the aseptic techniques was observed among 19\%-100\% of intravenous drug preparation and administration cases of that study. ${ }^{4}$ Aseptic techniques alone cannot guarantee that a sterile dose will ultimately be prepared, because environmental contamination can occur during the preparation and administration. It is often argued that aseptically prepared medicines for parenteral administration should be made in a controlled environment in a pharmacy department, where the risk of environmental contamination is lower than in the clinical environment. ${ }^{6}$ However, there is little evidence to support this argument.

Microbial contamination of parenterally prepared medicines is quite common. According to a systematic review on microbiological contamination rates of doses prepared using aseptic techniques in different environments, $7 \%$ of prepared doses were contaminated (coverage of the evidence: 19502007). ${ }^{5}$ The contamination rates were higher when medicines were prepared in hospital wards rather than in a pharmaceutical environment. ${ }^{5}$ The same authors updated the systematic review and meta-analysis in 2015 to cover the evidence published in 1950-2014. ${ }^{7}$ The first systematic review found the overall contamination rates for doses prepared in clinical environments to be $5 \%$ for individual doses and 2\% for doses prepared as part of a batch. ${ }^{5}$ Rates for doses prepared in pharmaceutical environments were found to be $2 \%$ for individual doses and $0 \%$ for doses prepared as part of a batch. ${ }^{5}$ In the recent update in 2015 , there was a higher frequency of contamination of doses prepared in a clinical rather than in a pharmaceutical environment ( $3.7 \%$ vs $0.5 \%$, respectively). ${ }^{7}$

The above-mentioned two systematic reviews by Austin and Elia ${ }^{5}$ compared the contamination 
rates between the different environments, but they did not focus on the different aseptic techniques applied to the preparation of parenteral medicines. The aseptic techniques can differ in many ways, for example, by practices related to working area, personal hygiene, reagents and media and handling. The aim of this systematic study was to focus on these different aseptic techniques in order to identify (1) incorrect practices in aseptic medicine preparation and administration and (2) recommendations for safer practices in hospitals.

\section{METHODS}

\section{Study design}

A systematic review based on the literature search in PubMed covering years 2007-2015 was carried out (figure 1). The quality of included studies was assessed using the GRADE system.

\section{Search strategy, inclusion criteria and data extraction}

A systematic literature search was conducted in PubMed covering the period from January 2007 to April 2015. This period was chosen as we wanted to focus on the most recent evidence published in peer-reviewed journals and indexed in PubMed. The search strategy, search terms and search engine from the first systematic review by Austin and Elia ${ }^{5}$ were applied. Studies were included if they concerned aseptic medicine preparation and administration in hospitals by different healthcare professionals, assessed incorrect practices and made recommendations for safer aseptic preparation and administration. Our inclusion criteria covered microbiological contamination (bacteria or fungi) of all parenteral products when prepared or administered to patients (also cytostatics and parenteral nutritions) in inpatient care.

We also included letters, editorials and commentaries from peer-reviewed journals because they reflect ongoing scientific debate on important issues at the time of publication. The exclusion criteria were studies not published in English, all animal studies and studies which covered food. In short, the following
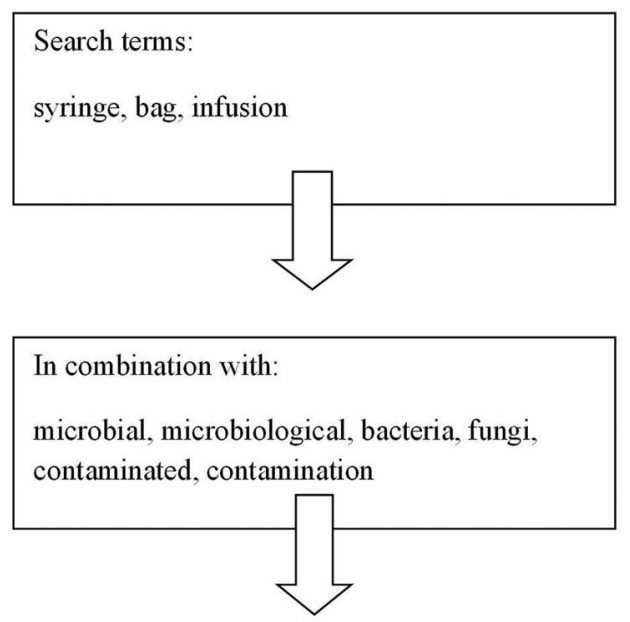

Combinations of infusion with bacteria and
infusion with fungi were combined for an
additional third term:
prepared. manufactured. compounded

Figure 1 Search strategy for PubMed indicating the used search terms and their combinations.
PICO (P - Populations/People/Patient/Problem, I - Intervention(s), $\mathrm{C}$ - Comparison and $\mathrm{O}$ - Outcome) was applied in this study: Participants (different healthcare professionals), Intervention (aseptic medicine preparation and administration), Comparison (different environments/different aseptic techniques/different professionals; not required) and Outcomes (appropriate and incorrect practices in aseptic preparation, and medication safety).

All searches were merged (figure 1). The search resulted in a total of 3242 references after duplicates were removed (figure 2). There were 3099 references after the exclusion of studies not published in English, 1326 after the exclusion of animal studies and 1268 after the exclusion of studies on the contamination of food. The title of each of these 1268 references was evaluated by one author (ES-P), and after excluding those that were irrelevant to the topic under investigation (eg, those dealing with stability or drug effectiveness) or whose title had not clearly stated the real subject, 102 references were left. After data extraction by title review, the abstracts of all 102 references were evaluated for relevance by one author (ES-P), resulting in 31 references. A review of the full text of each of these was carried out independently by two authors (ES-P and SH). Disagreements between the reviewers were resolved through discussion. Studies were retained only if they clearly met the inclusion criteria.

Two of the authors (ES-P and MA) assessed the quality of the included studies using the GRADE system with discussion to resolve disagreements. ${ }^{8}$ This systematic review adheres to the PRISMA guidelines for undertaking and presenting systematic reviews. $^{9}$

\section{Analysis of the data}

From included studies, we searched the incorrect practices and recommendations for safer practices in aseptic medicine preparation and administration in hospitals. The following issues of the included studies were analysed: contamination rates of prepared and administered medicines; impact of the environment on the contamination rates; typical medicines to prepare aseptically; the method for microbiological analyses and the appropriate and incorrect preparation and administration practices. We classified the practice to be appropriate if there was a guideline, recommendation or research result that was referred in the study to support the use of the chosen practices to avoid contamination. Likewise, we classified the practice to be incorrect if the included studies showed microbial contamination when using this practice. Based on this analysis of the included studies, we classified the incorrect practices found and the recommendations for safer practices into different categories. We made the description of each practice according to the evidence provided in the studies.

\section{RESULTS}

This systematic review is based on 26 peer-reviewed articles, of which $19^{10-28}$ were original articles with empirical results (see online supplementary appendix 1). The key findings of the review are reported in table 1 . The settings of the included articles are presented in online supplementary appendix 1 . Twelve of these included articles dealt with incorrect practices and recommendations to avoid contamination. ${ }^{10-12} 16 \quad 18-202426272930$ Thus, these were the key studies that provided empirical evidence to our research questions. These 12 studies concerned reasons for incorrect practices; description of incorrect practices that lead to contamination and recommendations to avoid contamination.

The majority of the included articles $(69 \%, n=18)$ were graded as low quality because they were non-randomised. Three 


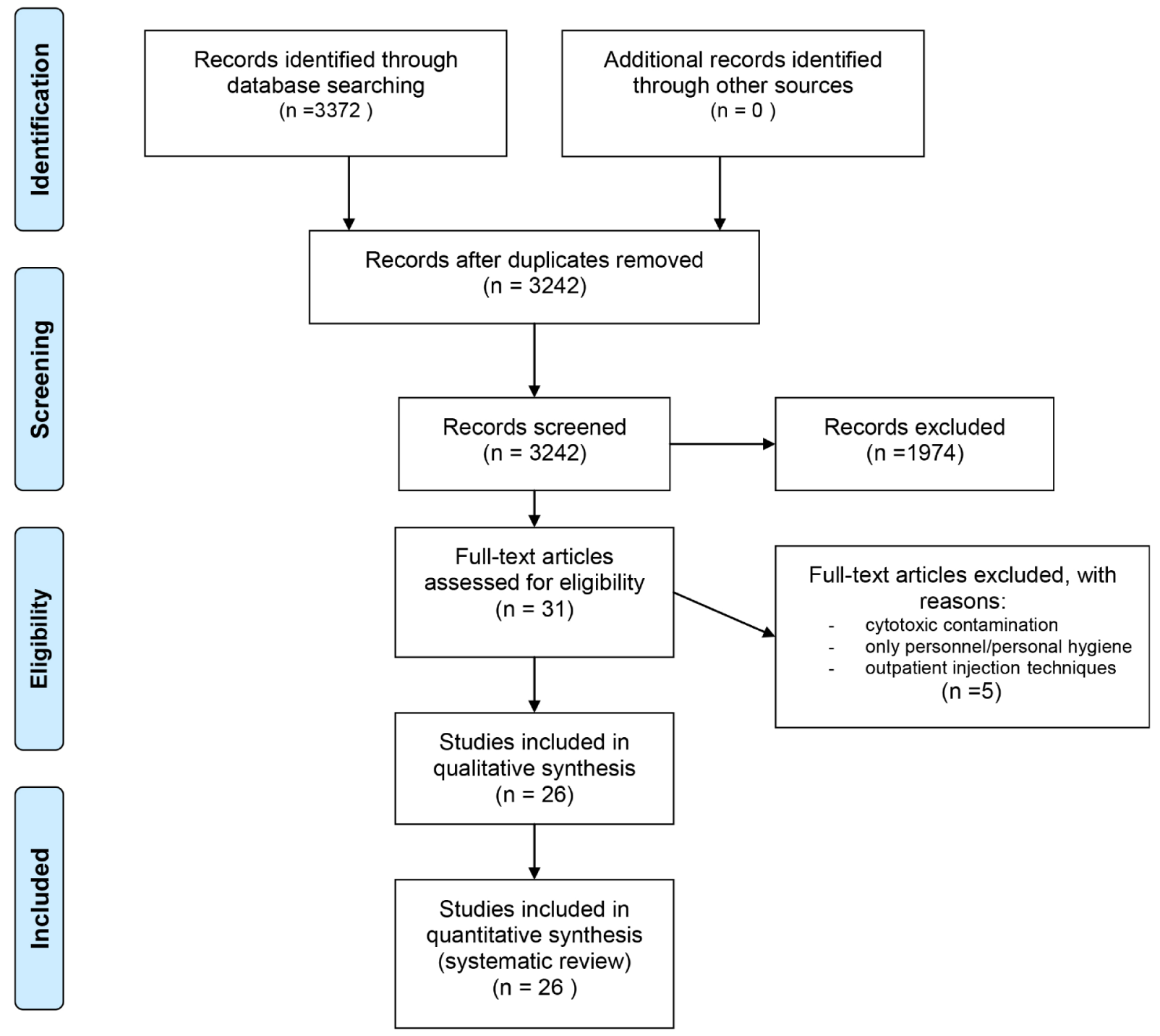

Figure 2 Flow chart of the study selection process.

of the original articles and all of the letters $(n=2),{ }^{31} 32$ editorials $(n=1)^{29}$ and commentaries $(n=2)^{33} 34$ were graded as very low quality because they were, for example, guidelines in their nature without empirical evidence (see online supplementary appendix 1, Objective and Study design).

Three of the 12 key studies (table 1) compared practical aseptic techniques and contamination rates between nurses and pharmacists in medicine preparation or administration. ${ }^{10} 11 \quad 17$ Three studies had been conducted only among nurses. ${ }^{16} 2130$ The remaining studies $(n=6)$ had been conducted among various healthcare professionals or not conducted among personnel at all. ${ }^{12} \quad 18 \quad 19202426$ These 12 key studies had been carried out in different environments: 8 of the studies were conducted in clinical ${ }^{1011} 121619212430$ and 1 in pharmaceutical ${ }^{20}$ environments. Two of the studies compared clinical and pharmaceutical environments. ${ }^{26} 27$ The contamination rates varied depending on the environment, profession or administration and preparation practices, ranging from $0 \%$ to $16 \%$ (see online supplementary appendix 1). Based on the data extracted from the included articles, it is indicated that pharmacy practitioner's aseptic skills are better than those of nurses ${ }^{10}$ and environmental (laminar-airflow hood in a cleanroom, drug preparation area in hospital ward or uncontrolled decentralised pharmacy in a ward) aspects in pharmacy units are cleaner than in wards. ${ }^{26}$

\section{Incorrect practices that led to contamination of parenteral medicines}

From the included articles with empirical evidence $(n=12$, table 1$)$, we identified 11 incorrect practices that led to contamination in aseptic preparation and/or administration of medicines in hospitals. The most common of these incorrect practices were: incorrect aseptic techniques (five studies); ${ }^{10} 19272930$ multiple use of syringes (one study), ${ }^{12}$ phials and ampoules (two studies) ${ }^{16}{ }^{19}$ and environmental aspects (one study). ${ }^{26}$

Incorrect aseptic technique, poor training and lack of experience (five studies)

Microbiological contamination during preparation was the most critical failure mode. ${ }^{10} 1923272930$ Aseptic techniques are required to manipulate central venous lines and prepare doses for intravenous administration. ${ }^{10} 2526$ Training and practice in the use of aseptic techniques may differ between healthcare workers, which lead to different risks of catheter-related sepsis. $^{10}$ 
Table 1 The key findings and recommendations of the included articles $(n=12)$ with empirical evidence on incorrect practices that lead to contamination in aseptic preparation and/or administration of medicines in hospitals and recommendations to avoid contamination according to the type of the recommendation (studies presented in alphabetical order)

\begin{tabular}{|c|c|c|c|c|}
\hline Study & $\begin{array}{l}\text { Reasons/incorrect practices that lead } \\
\text { to contamination }\end{array}$ & Recommendations to avoid contamination & Profession & $\begin{array}{l}\text { Clinical or pharmacy-based } \\
\text { preparation or } \\
\text { administration }\end{array}$ \\
\hline \multicolumn{5}{|l|}{ Disinfection } \\
\hline $\begin{array}{l}\text { Austin and } \\
\text { Elia }^{10}\end{array}$ & $\begin{array}{l}\text { 1. Nurses did not clean the working } \\
\text { surface or ampoule necks and did } \\
\text { not use gloves }\end{array}$ & $\begin{array}{l}\text { 1. Cleaning the working surface with detergents } \\
\text { and disinfectants (eg, } 70 \% \text { isopropyl alcohol or } \\
\text { ethanol) with proper technique } \\
\text { 2. Use of gloves } \\
\text { 3. Cleaning each ampoule neck and rubber septa } \\
\text { with alcohol swab before opening }\end{array}$ & $\begin{array}{l}\text { Nurses and } \\
\text { pharmacists }\end{array}$ & Clinic \\
\hline $\begin{array}{l}\text { Gargiulo } \\
\text { et }\left.a\right|^{19}\end{array}$ & $\begin{array}{l}\text { 2. Lack of hand hygiene, no } \\
\text { disinfection of phial septa or } \\
\text { intravenous ports and multiple use } \\
\text { of syringes }\end{array}$ & $\begin{array}{l}\text { 4. Hand washing and hand disinfection } \\
\text { 5. Disinfection of the intravenous ports }\end{array}$ & Anaesthetists & Clinic \\
\hline Gorski $i^{21}$ & $\begin{array}{l}\text { 3. Lack of infection prevention in } \\
\text { peripheral intravenous catheter use } \\
\text { and alternative site infusions }\end{array}$ & 6. Skin antisepsis before catheter placement & Nurses & Clinic and home \\
\hline \multicolumn{5}{|l|}{ Catheter care } \\
\hline Gorski $i^{21}$ & $\begin{array}{l}\text { Lack of infection prevention in peripheral } \\
\text { intravenous catheter use and alternative } \\
\text { site infusions }\end{array}$ & 1. Checking and caring the catheter site daily & Nurses & Clinic and home \\
\hline $\begin{array}{l}\text { Yoshida } \\
\text { et } a l^{27}\end{array}$ & $\begin{array}{l}\text { 4. Character of ward and catheter } \\
\text { placement time }\end{array}$ & 2. Catheter placement not more than 30 days & $\begin{array}{l}\text { Nurses and } \\
\text { pharmacists }\end{array}$ & $\begin{array}{l}\text { Clinic and pharmacy } \\
\text { departments }\end{array}$ \\
\hline \multicolumn{5}{|c|}{ Equipments and medicines } \\
\hline $\begin{array}{l}\text { Bertoglio } \\
\text { et } a /^{11}\end{array}$ & $\begin{array}{l}\text { 5. Manually filled (filled by a nurse or } \\
\text { a pharmacist in a hospital ward) } \\
\text { syringes }\end{array}$ & 1. Using of manufactured prefilled syringes & $\begin{array}{l}\text { Nurses and } \\
\text { pharmacists }\end{array}$ & Clinic \\
\hline $\begin{array}{l}\text { De Smet } \\
\text { et } a l^{16}\end{array}$ & $\begin{array}{l}\text { 6. Multiple dose phials with a high } \\
\text { nutrient content }\end{array}$ & $\begin{array}{l}\text { 2. Singe use of flushing solutions with low } \\
\text { nutrient content }\end{array}$ & Nurses & Clinic \\
\hline Buerke et $a l^{12}$ & 7. Multiple use & 3. Single use of syringes in automatic injectors & $\begin{array}{l}\text { Technical and } \\
\text { medical staff }\end{array}$ & CT department (clinic) \\
\hline $\begin{array}{l}\text { Nakataki } \\
\text { et } a^{30}\end{array}$ & 8. Improper handling & 4. Aseptic handling of infusion set needles & Nurses & Clinic \\
\hline $\begin{array}{l}\text { Rangel-Fausto } \\
\text { et }\left.a\right|^{24}\end{array}$ & 9. Open infusion containers & 5. Use of closed infusion containers & $\begin{array}{l}\text { Physicians, nurses } \\
\text { and paramedical } \\
\text { staff }\end{array}$ & Clinic \\
\hline Dolan et $a l^{18}$ & N/A & $\begin{array}{l}\text { 6. Single use of syringes, disposable tubes and } \\
\text { connectors of automatic injectors } \\
\text { 7. Discarding all opened phials, intravenous } \\
\text { solutions and opened syringes }\end{array}$ & $\mathrm{N} / \mathrm{A}$ & N/A \\
\hline \multicolumn{5}{|l|}{ Storing } \\
\hline Dolan et $a l^{18}$ & N/A & $\begin{array}{l}\text { 1. Storing medications in a clean area on a clean } \\
\text { surface } \\
\text { 2. Storage of needles and syringes never } \\
\text { unwrapped } \\
\text { 3. Preparation of IV solutions as close as possible } \\
\text { to administration }\end{array}$ & N/A & $\mathrm{N} / \mathrm{A}$ \\
\hline \multicolumn{5}{|c|}{ Working environment } \\
\hline Dolan et al ${ }^{18}$ & $N / A$ & $\begin{array}{l}\text { 1. Drug preparation in laminar flow hood } \\
\text { 2. Avoiding to contact sterile drugs or sterile } \\
\text { areas with non-sterile objects }\end{array}$ & N/A & $\mathrm{N} / \mathrm{A}$ \\
\hline Stucki et $a^{26}$ & 10. Environmental aspects & 3. Working in cleanrooms when ever possible & Single operator & $\begin{array}{l}\text { Clinic and pharmacy } \\
\text { department }\end{array}$ \\
\hline \multicolumn{5}{|c|}{ Quality of prepared medications } \\
\hline $\begin{array}{l}\text { Gershman } \\
\text { et } a 2^{20}\end{array}$ & 11. No auditing for suppliers & $\begin{array}{l}\text { 1. Checking suppliers to ensure that medications } \\
\text { ordered are produced according to } \\
\text { manufacturing regulations }\end{array}$ & $\mathrm{N} / \mathrm{A}$ & Pharmacy department \\
\hline
\end{tabular}

$\mathrm{N} / \mathrm{A}$, not available.

Sigward et $a l^{25}$ studied the aseptic technique of pharmacy practitioners with aseptic simulation test where all septa of the phials to be manipulated were contaminated. The aseptic simulation test or media-fill test procedure uses a sterile microbiological growth medium (tryptone soya agar) in place of the drug solution to test whether the aseptic practices are adequate to prevent contamination during actual drug production. Usually, the test is done annually in the pharmaceutical industry and in hospital pharmacies. ${ }^{25}$ Sigward et $a l^{25}$ showed in their study that when a pharmacy practitioner used a correct aseptic 
technique they passed the aseptic simulation test. They also showed that the microbiological growth in the simulation test directly correlated to erroneous handling and a poor aseptic technique. Austin and Elia ${ }^{10}$ showed that pharmacy practitioners achieved a significantly lower syringe contamination rate than nurses and the main reason for that was training and experience that was based on education. ${ }^{10}$ Isanhart $e t a l^{22}$ showed that among pharmacy students an improved aseptic technique reduced the rate of microbial contamination. Training and experience were associated with different operational procedures. The stages of aseptic techniques are presented in table 1, of which the most important are disinfection and catheter care.

\section{Multiple use of syringes, phials and ampoules (three studies)}

We found three studies which concerned the multiple use of syringes, phials and ampoules. ${ }^{12} 16{ }^{19}$ A single-dose or single-use phial and syringe are a dosage forms of liquid medication intended for parenteral administration (injection or infusion) that are meant for use in a single patient for administration of a single dose. Single-dose or single-use medicines do not typically contain an antimicrobial preservative and they are licensed solely to be used as a single dose or for single use. The microbial contamination can occur after the first penetration of the single dose. Two of the included articles reported outbreaks resulting from healthcare personnel using single-dose or singleuse phials for multiple patients. ${ }^{32}{ }^{34}$ The multiple use of syringes, phials and ampoules (table 1) for more than one patient increases the risk of microbial contamination. ${ }^{18}$ The multiple use is a practice where the same syringe, phial or ampoule is used for more than once and on more than one patient. ${ }^{18}$ The multiple use of prefilled syringes has been imagined to save time and to be more effective. Buerke et $a l^{12}$ showed that the time of assembly of the injection system and installation of prefilled syringes did not differ significantly between the single use protocol and multiple-use protocol and there is the risk of bacterial contamination with multiple use of syringes. ${ }^{12}$ Many studies on injection practices show that physicians are not aware of the risks of multiple use of syringes. ${ }^{32}{ }^{34}$ A survey of 550 healthcare professionals found that $1 \%$ of clinicians reported sometimes reusing syringes and $6 \%$ reported reusing single-dose phials. ${ }^{35}$ According to Cozanitis and Mäkelä, ${ }^{32}$ syringe reuse is a very common practice among anaesthetists. Rosenberg et $a l^{36}$ showed almost $40 \%$ of anaesthetists admitted to multiple use of syringes.

\section{Direct influence of environmental cleanliness on the quality of} end products (two studies)

One of the main factors that contributes to microbial contamination of drugs is the cleanliness of the work environment. ${ }^{20} 26$ When medicinal preparations are not prepared in an aseptic environment, it is recommended that the drug is administered soon after reconstitution to avoid microbial contamination. ${ }^{18} 37$ However, in some situations, drugs are prepared ahead of time and stored until they are needed. Stucki et $a l^{26}$ showed that microbial contamination of prepared syringes containing sterile media correlates with the rate of environmental contamination. Working with a correct aseptic technique within a cleanroom was demonstrated to be the best way to avoid bacterial or fungal contamination of injectable drugs directly resulting in patient infections. Furthermore, working in a cleanroom is a premise if the period of drug storage is extended. ${ }^{26}$ But when working in hospital wards without cleanrooms, the competency and carefulness of the operator is especially important. The operator has to use safe preparation and administration practices to avoid contamination. ${ }^{26}$

Recommendations for safe practices to avoid contamination of parenteral medicines (12 studies, 22 recommendations)

Twenty-two recommendations were found for safe practices to avoid microbial contamination in different operational procedures (table 1). They were categorised into the following six key recommendation categories: disinfection (six recommendations); catheter care (two recommendations); equipments and medicines (seven recommendations), storage (three recommendations), working environment (three recommendations) and quality of prepared medicines (one recommendation) (table 1).

\section{Letters, editorials, columns, brief reports and commentaries (seven articles)}

Included letters $(n=2)$, editorials $(n=1)$, columns $(n=1)$, brief reports $(n=1)$ and commentaries $(n=2)$ reflected ongoing scientific debate on the same issues related to safe aseptic preparation and administration of parenteral medications as evidenced in empirical studies described above. ${ }^{29-34} 38$ They raised the issues of multiple use of syringes and unsafe injection practices, which increase the risk of microbial contamination. ${ }^{30} 32 \quad 3438$ They called for new technologies and new control methods to identify contamination sources in medicine preparation. ${ }^{31}{ }^{33}$

\section{DISCUSSION}

This systematic review found 11 incorrect practices that increased the risk of contamination of parenteral medicines. The most reported incorrect practices were multiple use of phials and syringes and lack of overall disinfection during the aseptic preparation and administration. Twenty-two practices were recommended to avoid contamination. Most of the recommendations relate to categories disinfection and equipments and medicines. The results indicate that pharmacists prepared syringes with less contamination than nurses because of the pharmacist's aseptic skills and environmental aspects in pharmacy units.

Hand hygiene and hand disinfection are the most important disinfection procedures ${ }^{19}$; however, careful surface, ${ }^{10}$ injection port, ${ }^{19}$ catheter, ${ }^{21}$ neck of ampoules, ${ }^{10}$ rubber septa ${ }^{10}$ and patient skin disinfection ${ }^{21}$ also decrease the risk of microbial contamination of prepared and administered parenteral medicines. The multiple use of phials and syringes should be avoided. ${ }^{18}$ Newly introduced procedures should be assessed to control their infection risks. These procedures could be, for example, alcohol hand hygiene and desinfection phial gums and injection ports. In the USA, the Centers for Medicare and Medicaid Services is responsible for ensuring that healthcare facilities comply with infection prevention health and safety standards, for example, that single-use phials or single-dose phials are not used for more than one patient. ${ }^{37}$

Based on the data extracted from the included studies, it is indicated that pharmacy practitioner's aseptic skills are better than those of nurses ${ }^{10}$ and environmental (laminar-airflow hood in a cleanroom, drug preparation area in hospital ward or uncontrolled decentralised pharmacy in a ward) aspects in pharmacy units are cleaner than in wards. ${ }^{26}$ The most likely reason for differences in contamination rates between nurses and pharmacists concerns their respective training and experience in aseptic techniques. ${ }^{10}$ In the hospital wards, the medicine preparation is often performed in patient rooms, without any protective wear, ${ }^{19}$ while in the hospital pharmacies the preparation is done in cleanrooms with regulating protective wear. 
Environmental standards and preparation practices in hospital wards are variable. There are no national standards for wardbased aseptic preparation, while the preparation in hospital pharmacies is well instructed. ${ }^{10}$ Therefore, the demand for making parenterally used medicines in a pharmacy department is well founded. Recent research has started to pay attention to the aseptic techniques for all administration procedures and infusion solution/medication preparation, after incorrect aseptic techniques and environmental aspects have been identified. ${ }^{15} 21$ As a result, to prevent contamination and bloodstream infections, checklists and safety tools have been developed and used. $^{2115}$ The compliance of hospital staff with the given rules is often poor. ${ }^{15}$ De Giorgi et al ${ }^{15}$ showed, based on a pharmacoeconomic analysis, that the involvement of a clinical pharmacist is one of the most cost-effective interventions in reducing microbiological contamination in patient care.

Our results showed that there is lack of quality in manufactured infusates (see online supplementary appendix 1). Infections due to contaminated infusates are a serious threat. The use of contaminated solutions may lead to a large and severe epidemic, and because of that it is important that manufacturers as well as compounding pharmacies follow guidelines and regulations to guarantee the quality of preparations. Infection control teams in organisations also play an equally important role in noting contaminated sources. Furthermore, public health entities have an important role in effectively communicating information in these kinds of cases. ${ }^{20} 31$ More co-ordination between healthcare centres and governing bodies is needed for rapid identification of contaminated solutions in the future. ${ }^{13}$

Some authors believe that manual aseptic filling in flow cabinets of cleanrooms is technology nearing the end of its use as regulations have been tightened and there are many new technologies available. ${ }^{13}$ The fact is inevitable that human operators are the major, some would claim only, significant risk modality in aseptic processing. To continue to guarantee the quality of hand or manual aseptic filling, we have to adopt these new technologies. They include items such as in-line depyrogenation of containers, automatic weight-check, machine controls, such as no container-no fill, improved component handling, electronic adjustments and significantly separative technologies such as closed isolators. ${ }^{13}$ Some companies have begun to perform manufacturing under the guise of compounding. Firms are trying to capitalise on the regulatory exemptions afforded to compounded products to produce less expensive medicinal products. Thus, it is important to check out suppliers of medicinal products to ensure that medications ordered are produced according to manufacturing regulations. ${ }^{20}$

\section{Study strengths and limitations}

We exploited the previous systematic review and its search strategy. ${ }^{5}$ We also intentionally used only PubMed as a search engine as we wanted to repeat the literature search by Austin and Elia, ${ }^{5}$ but wanted to take another approach by identifying incorrect aseptic techniques and practices that lead to contamination in preparation and administration of parenteral medications. The data extraction by titles and abstracts were conducted by one author, which has potential for a selection bias, ${ }^{9}$ in selection of which studies to include in review to present the most significant result. In turn, two authors evaluated the full texts, which improve the reliability of the synthesis of the evidence. The included studies applied different study designs and protocols, as well as different measures and indicators to assess the possible contamination of parenteral preparations, which make it difficult to compare and generalise their findings. Protocols in most of the included studies were designed for ward-based or pharmacy-based aseptic preparation in such a way that aseptic practices were seen as the only leading cause to contamination. Therefore, the possibility of manufacture-based contaminations might have been overlooked.

\section{Practical implications}

Our study provides the most current evidence on safety risks and possible ways to minimise the risks in aseptic preparation and administration of medicines in hospitals. Our review found differences in contamination rates between different healthcare workers in preparing medicines as has been found in the previous systematic reviews (Austin and Elia ${ }^{5}$ and and Austin et $a l^{7}$ ). We also found many incorrect aseptic techniques and practices that should be avoided and many good techniques and practices that should be used instead. The new safer techniques and practices, for example, disinfection and hygiene aspects, should be implemented and taught to healthcare practitioners, particularly to nurses. As the change for the better in contamination rates of administered medicines seems to be challenging to achieve in hospitals, ${ }^{7}$ better and possibly international procedures for safe parenteral practices need to be developed.

\section{CONCLUSION}

This systematic review identified many incorrect and unsafe practices and disregarded given rules in aseptic preparation and administration of parenteral medicines. This study indicates that current preparation and administration systems for parenteral therapy do not minimise patient safety risks. As a consequence, both theoretical knowledge and practical skills required in safe preparation and administration of parenteral medications should be improved among healthcare practitioners. As the change for the better in contamination rates of administered medicines seems to be challenging to achieve in hospitals, better and possibly international procedures for safe parenteral practices need to be developed.

Contributors The following contributorship statement applies to each author of this manuscript: substantial contributions to the analysis of data for the work; revising the work critically for important intellectual content; final approval of the version to be published; agreement to be accountable for all aspects of the work in ensuring that questions related to the accuracy or integrity of any part of the work are appropriately investigated and resolved.

Funding Eeva Suvikas-Peltonen was supported by the state research funding granted by Satakunta Hospital District when completing the review.

Competing interests None declared.

Provenance and peer review Not commissioned; externally peer reviewed.

\section{REFERENCES}

1 Rothberg A. Lessons from the investigation into intravenous fluid-related neonatal deaths. S African Med J 1992;81:397-8.

2 Frean JA, Arntzen L, Rosekilly I, et al. Investigation of contaminated parenteral nutrition fluids associated with an outbreak of Serratia odorifera septicaemia. J Hosp Infect 1994;27:263-73.

3 Noskin GA, Rubin RJ, Schentag JJ, et al. The burden of Staphylococcus aureus infections on hospitals in the United State: an analysis of the 2000 and 2001 nationwide inpatient sample database. Arch Intem Med 2005;165:1756-61.

4 Cousins DH, Sabatier B, Begue D, et al. Medication errors in intravenous drug preparation and administration: a multicentre audit in the UK, Germany and France. Qual Saf Health Care 2005;14:190-5.

5 Austin P, Elia M. A systematic review and meta-analysis of the risk of microbial contamination of aseptically prepared doses in different environments. J Pharm Pharmaceut Sci 2009;12:233-42.

6 Beaney AM. Quality assurance of aseptic preparation services. 4th edn. Pharmaceutical Press, 2006;107.

7 Austin PD, Hand KS, Elia M. Systematic review and meta-analysis of the risk of microbial contamination of parenteral doses prepared under aseptic techniques in 
clinical and pharmaceutical environments: an update. J Hosp Infect 2015;91:306-18.

8 Guyatt GH, Oxman AD, Kuntz R, et al. What is "quality of evidence" and why is it important to clinicians? BMJ 2008;336:995-8.

9 Moher D, Liberati A, Tetzlaff J, et al. Preferred reporting items for systematic reviews and meta-analyses: the PRISMA statement. Ann Intern Med 2009;151:264-9.

10 Austin P, Elia M. Improved aseptic technique can reduce variable contamination rates of ward-prepared parenteral doses. J Hosp Infect 2013:83:160-3.

11 Bertoglio S, Rezzo R, Merlo FD, et al. Pre-filled normal saline syringes to reduce totally implantable venous access device-associated bloodstream infection: a single institution pilot study. J Hosp Infect 2013;84:85-8.

12 Buerke $B$, Puesken $M$, Mellmann A, et al. Microbiologic contamination and time efficiency of use of automatic MDCT injectors with prefilled syringes: results of a clinical investigation. AJR Am J Roentgenol 2010;194:299-303.

13 Chemaly RF, Rathod DB, Sikka MK, et al. Serratia marcescens bacteremia because of contaminated prefilled heparin and saline syringes: a multi-state report. Am J Infect Control 2011;39:521-4.

14 Crill CM, Hak EB, Robinson LA, et al. Evaluation of microbial contamination associated with different preparation methods for neonatal intravenous fat emulsion. Am J Health Syst Pharm 2010;67:914-18.

15 De Giorgi I, Fonzo-Christie C, Cingria L, et al. Risk and pharmacoeconomic analyses of the injectable medication process in the paediatric and neonatal intensive care units. Int J Qual Health Care 2010;22:170-8.

16 De Smet B, Veng C, Kruy L, et al. Outbreak of Burkholderia cepacia bloodstream infections traced to the use of Ringer lactate solution as multiple-dose vial for catheter flushing, Phnom Penh, Cambodia. Clin Microbiol Infect 2013;19:832-7.

17 Souza Dias MB, Habert AB, Borrasca $V$, et al. Salvage of long-term central venous catheters during an outbreak of Pseudomonas putida and Stenotrophomonas maltophilia infections associated with contaminated heparin catheter-lock solution. Infect Control Hosp Epidemiol 2008;29:125-30.

18 Dolan SA, Felizardo G, Barnes S, et al. APIC position paper: safe injection, infusion, and medication vial practices in health care. Am J Infect Control 2010;38:167-72.

19 Gargiulo DA, Sheridan J, Webster CS, et al. Anaesthetic drug administration as a potential contributor to healthcare-associated infections: a prospective simulation-based evaluation of aseptic techniques in the administration of anaesthetic drugs. BMJ Qual Saf 2012;21:826-34.

20 Greshman MD, Kennedy DJ, Noble-Wang J, et al. Multistate outbreak of Pseudomonas fluorescens bloodstream infection after exposure to contaminated heparinized saline flush prepared by a compounding pharmacy. Clin Infect Dis 2008;47:1372-9

21 Gorski LA. Central venous access device associated infections: recommendations for best practice in home infusion therapy. Home Healthc Nurse 2010;28:221-9.
22 Isanhart CM, McCall KL, Kretschmer D, et al. Parenterals laboratory course to reduce microbial contamination rates in media fill test performed by pharmacy students. Am J Pharm Educ 2008;72:27.

23 Kerenyi M, Borza Z, Csontos C, et al. Impact of medications on bacterial growth in syringes. J Hosp Infect 2011;79:265-6.

24 Rangel-Fausto MS, Higuera-Ramirez F, Martinez-Soto J, et al. Should we use closed or open infusion containers for prevention of bloodstream infections? Ann Clin Microbiol Antimicrob 2010:9:6.

25 Sigward E, Fourgeaud M, Vazquez R, et al. Aseptic simulation test challenged with microorganism for validation of pharmacy operations. Am J Health Syst Pharm 2012;69:1218-24.

26 Stucki C, Sautter AM, Favet J, et al. Microbial contamination of syringes during preparation: the direct influence of environmental cleanliness and risk manipulations on end-product quality. Am J Health Syst Pharm 2009;66:2032-6.

27 Yoshida J, Ishimaru T, Fujimoto $\mathrm{M}$, et al. Risk factors for central venous catheter-related bloodstream infection: a 1073-patient study. J Infect Chemother 2008;14:399-403.

28 Younger $G$, Khan M. Setting up and priming an intravenous infusion. Nurs Stand 2008;22:40-4.

29 Gorski LA. Infusion nursing in the US: trends and challenges. Br J Nurs 2013; 22:S3.

30 Nakataki $\mathrm{E}$, Oto J, Hata $\mathrm{M}$, et al. Incidence of bacterial contamination in infusion set needles. Am J Infect Control 2013;41:273-4.

31 Chemaly RF, Rathod DB, Raad II. A tertiary care cancer center experience of the 2007 outbreak of Serratia marcescens bloodstream infection due to prefilled syringes. Infect Control Hosp Epidemiol 2009;30:1237-8.

32 Cozanitis DA, Mäkelä P. The contaminated syringe: harming the patient's good. Acta Anaesthesiol Scand 2009; 53:548.

33 Agalloco J, Akers J, Baseman $\mathrm{H}$, et al. Risk management, cGMP, and the evolution of aseptic processing technology. PDA J Pharm Sci Technol 2009;63:8-10.

34 Kuehn BM. Unsafe injection practices plague US outpatient facilities, harm patients. JAMA 2012;308:2551-2.

35 Pugliese G, Gosnell C, Bartley JM, et al. Injection practices among clinicians in United States health care settings. Am J Infect Control 2010;38:789-98.

36 Rosenberg AD, Bernstein DB, Bernstein RL, et al. Accidental needlesticks: do anesthesiologists practise proper infection control precautions? Am J Anesthesiol 1995;22:125-32

37 Simmons BP, Hooton TM, Wong ES, et al. Centers for disease control guidelines on infection control: guidelines for prevention of intravascular infections. Atlanta: Centers for Disease Control, 1981. PB84-923403.

38 McCrea MK. No excuse for unsafe injection practices. AORN J 2013;97:132-5. 